•生物编目・

\title{
美国在华采集竹类植物标本的历史(1840-2010年)
}

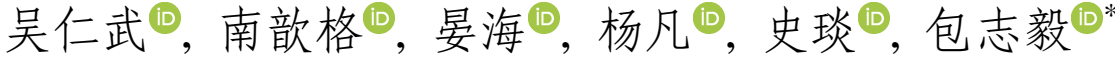

浙江农林大学风景园林与建筑学院, 杭州 311300

摘要: 植物标本采集是植物学研究的重要内容, 与植物引种密切相关。自19世纪以来, 美国植物采集者在全球尤其是中国进 行了广泛的植物采集。在众多的植物类群中, 中国的竹类植物引起了美国采集者的极大关注, 并开展了大量调查研究和标本 采集工作。研究美国植物采集者在中国采集竹类植物标本的历史, 对了解竹类植物从中国引种到美国的历史具有重要意义。 本文基于国内外有关美国在华采集的竹类植物标本数据，对其学名、采集地、采集人以及采集时间进行整理校对，分析了美 国采集者在华采集竹类植物标本的历史。结果表明：1840-2010年，美国在华共采集竹类植物标本960号2,238份，隶属于25属 120 种(含变种和变型), 分别占中国竹类属和种数的 $73.5 \%$ 和 $22.5 \%$; 有 45 位(支)采集者(采集队), 在这些采集者中莫古礼最为 重要; 采集地涉及20个省级行政区; 采集时间前后跨度约170年，主要集中在20世纪上半叶。

关键词: 中国; 美国采集者; 竹类植物; 标本; 采集历史; 植物资源

吴仁武，南歆格，晏海，杨凡，史琰，包志毅 (2021) 美国在华采集竹类植物标本的历史(1840-2010年). 生物多样性，29，960-970. doi: 10.17520/biods.2021029.

Wu RW, Nan XG, Yan H, Yang F, Shi Y, Bao ZY (2021) On the history of the bamboo specimen collection in China by American plant collectors (1840-2010). Biodiversity Science, 29, 960-970. doi: 10.17520/biods.2021029.

\section{On the history of the bamboo specimen collection in China by American plant collectors (1840-2010)}

Renwu Wu ${ }^{\mathbb{D}}$, Xinge Nan ${ }^{\mathbb{1}}$, Hai Yan ${ }^{\mathbb{D}}$, Fan Yang ${ }^{\mathbb{D}}$, Yan Shi ${ }^{\mathbb{D}}$, Zhiyi Bao ${ }^{(\mathbb{D} *}$

College of Landscape Architecture, Zhejiang A\&F University, Hangzhou 311300

\section{ABSTRACT}

Aim: Plant specimen collections are important for botany research and closely related with plant introductions. Studies show that American plant collectors had collected plants extensively worldwide, especially in China since the 19th century. Because of the ornamental value, cultural connotation, economic significance and ecological benefits, bamboo has become important for American plant collectors in China. Thus, it is essential to study the history of bamboo specimen collection in China by American plant collectors to understand the history of bamboo introduction in the United States from China.

Methods: In this study, we collected raw data with bamboo names, collector names, collection locations and dates from herbarium specimens. We corrected the scientific names of bamboo collected in China, reinvestigated the collection locations, collectors, and collection dates with the goal of investigating the history of bamboo specimens collected in China by American plant collectors.

Results: From 1840 to 2010, a total of 2,238 sheets and 960 numbers of bamboo specimens were collected in China, belonging to 25 genera (accounting for $73.5 \%$ of the genera in China) and 120 species (22.5\% of the species in China, including several varieties and forms). These specimens were collected by 45 collectors and collection teams and were predominantly from 20 provincial administrative regions. Among the collectors, McClure was the most important one for bamboo specimen collection. This research spanned approximately 170 years, with the majority of research taking place in the first half of the 20th century.

Conclusions: This study objectively reviewed the history of bamboo specimens collected by American plant collectors in China and analyzed the relevant genera, species, collectors, collection locations, collection times, historical

收稿日期: 2021-01-19; 接受日期: 2021-03-12

基金项目: 浙江农林大学科研发展基金(2021FR030)和杭州市哲学社会科学规划课题(Z21JC079)

* 通讯作者 Author for correspondence. E-mail: bao99928@188.com 
background, and contributions from expeditions and collections. The collection history of bamboo specimens show that American plant collectors have made remarkable achievements in bamboo collection from China. The investigation and collection of Chinese bamboo by American plant collectors promoted several applications for bamboo in the United States. First, bamboo was found to be an excellent ornamental and economic plant species. Second, there was an increased promotion for the development of bamboo taxonomy research. Third, there was a facilitation for the introduction and spread of Chinese bamboos to the United States. We suggest that the following work needs to be done for future studies: (1) research on the history of other plant expeditions, collections, and introductions from other Western countries' collectors, such as British, French, and German collectors; (2) research on plant collections and introductions from foreign countries into China.

Key words: China; American plant collectors; bamboo; specimen; collection history; plant resource

植物为生物多样性、城市绿化和人类身心健康 做出了巨大贡献(Rydin et al, 2012; World Health Organization, 2016; Lin et al, 2019; Zhu et al, 2019)。 植物标本采集是植物学研究的重要内容, 与植物引 种有密切关系。自19世纪以来, 美国植物采集者在 全球尤其是中国进行了广泛的采集(Cox, 1945; 俞 德浚, 1962; 苏雪痕, 1987)。威尔逊(Ernest Henry Wilson, 1876-1930)曾称中国是“世界花园之母”, 从 早春盛开的连尧(Forsythia suspensa)、玉兰(Yulania denudata)到夏季的牡丹(Paeonia suffruticosa)、月季 (Rosa chinensis)再到秋季的菊花(Chrysanthemum $\times$ morifolium), 无不证明中国具有丰富的植物资源 (Swingle, 1900; Wilson, 1929; Li, 1959; 马金双等, 2020)。如此丰富的植物资源吸引了众多的国外采集 者来华考察和采集植物(Smith, 1930; 罗桂环, 1994; 马金双, 2011)。

由于具有极高的观赏价值、文化内涵、经济价 值和生态效益, 竹类植物成为美国采集者在华采集 的重要植物类群(Galloway, 1925; McClure, 1956, 1966; Cunningham, 1984)。新中国成立前, 对竹类植 物的调查和标本采集主要是西方人, 20 世纪上半叶 更是以美国人为主。美国在华采集竹类植物标本的 历史对竹类植物作为经济植物和观赏植物从中国 引种到美国产生了深刻影响 (Fairchild, 1903; Ryerson, 1933; Maden, 2004), 然而对美国在华采集 竹类植物历史的研究则很少。

从19世纪开始, 美国就在华开展了综合性的植 物采集和引种。这些工作主要由美国农业部(United States Department of Agriculture, USDA)、哈佛大学 阿诺德树木园 (Arnold Arboretum, Harvard University)以及其他相关机构的威尔逊、梅耶(Frank Nicholas Meyer, 1875-1918)和洛克(Joseph Francis
Charles Rock, 1884-1962)等完成(Wilson, 1913; 罗 桂环, 2005)。此外, 教会学校岭南学校(Canton Christian College, CCC) 的莫古礼 (Floyd Alonzo McClure, 1897-1970)、金陵大学 (University of Nanking) 的史德蔚 (Albert Newton Steward, 1897-1959)等也非常有影响力(Stoner \& Hummer, 2007)。如莫古礼在华多地实地调研, 开展竹类植物 采集、引种和研究, 为竹子分类学的建立和发展以 及美国在华引种竹类植物做出了突出贡献(McClure, 1940a, b, c, 1941; Meyer, 1972)。然而, 他们在新中 国成立前采集的标本现在分布在世界各地的标本 馆, 缺少统一而专门的研究。

在植物采集史上，中国是采集时间最早最长、 采集人国别最多、采集种类最多、采集成果最丰富 的国家(Bretschneider, 1871; Fan, 2004; 马金双, 2014)。据统计，1640-1898年的258年间, 在中国采 集植物的西方者有334人(Bretschneider, 1898; Veitch, 1906; 赵铁桥, 1991a, b)。由于缺少对植物学名、采 集时间、采集人和采集地等信息的准确考证, 限制 了对竹类植物采集历史的全面认识。

本文基于采集者档案、标本数据以及现场调研, 全面验证所有可用的标本信息, 试图回答以下问题: (1)美国采集者在华采集竹类植物标本的数量; (2)采 集的标本属种、采集时间、采集地、采集人; (3)美 国在华采集和引种竹类植物代表人物莫古礼的采 集经历; (4)美国在华采集竹类植物对其竹类植物研 究及应用的影响。

\section{研究方法}

\section{1 数据来源}

数据源自中、美两国的相关大学、植物园、标 本馆及档案馆等的实地调研以及相关网站。数据收 
集截至2020年3月1日, 在植物标本数据方面, 共收 集整理出 960 号 2,238 份美国在华采集竹类植物标本 数据, 相关标本馆馆藏数据见表 1 。从这些数据中提 取种名、采集人、采集地以及采集日期等原始记录 信息, 结合查找到的相关采集人的档案材料, 综合 开展本研究。

\section{2 数据分析}

\subsection{1 学名核准}

竹类植物标本有最初的描述, 但由于竹子分类 学不断发展, 竹类植物属种命名变化较多, 本文在 原始记录的基础上, 结合后续植物学家对标本的鉴 定, 核实了准确的接受名。主要参考Flora of China
(Wu et al, 2006)、《中国植物志》(第九卷) (耿伯介和 王正平，1996)、The Bamboos of the World (Ohrnberger, 1999)以及 World Checklist of Selected Plant Families (https://wcsp.science.kew.org/)。

\subsection{2 地名考证}

根据文献记录的详细程度, 标本采集地和国内 直接引种地名一般确定至区县市一级，部分确定至 镇、村一级。在确定地名时, 需研究地名拼写以及 中国地方行政区划变更等。19世纪和20世纪上半叶 地名标注以威妥玛式(Wade-Giles spelling system)和 邮政式(postal spelling system)拼音为准。美国采集 者多不熟悉中文，这也给他们在采集过程中的地名

表1 竹类植物标本收藏机构基本信息

Table 1 The basic information of the herbarium for collecting bamboo specimens

\begin{tabular}{|c|c|c|c|c|}
\hline \multicolumn{2}{|c|}{$\begin{array}{l}\text { 序号标本馆名称及代码 } \\
\text { No. Herbarium name and }\end{array}$} & \multirow{2}{*}{$\begin{array}{l}\begin{array}{l}\text { 号数 } \\
\text { Numbers }\end{array} \\
735\end{array}$} & $\begin{array}{l}\text { 份数 } \\
\text { Sheets }\end{array}$ & $\begin{array}{l}\text { 地点 } \\
\text { Location }\end{array}$ \\
\hline 1 & $\begin{array}{l}\text { 美国自然历史博物馆植物标本馆 } \\
\text { National Museum of Natural History, US }\end{array}$ & & 1,211 & $\begin{array}{l}\text { 美国华盛顿特区 } \\
\text { Washington, DC, the United States (US) }\end{array}$ \\
\hline 2 & $\begin{array}{l}\text { 中山大学植物标本室 } \\
\text { Herbarium of Sun Yat-sen University, SYS }\end{array}$ & 614 & 801 & $\begin{array}{l}\text { 中国广东广州 } \\
\text { Guangzhou, Guangdong, China }\end{array}$ \\
\hline 3 & $\begin{array}{l}\text { 密苏里植物园植物标本馆 } \\
\text { Missouri Botanical Garden Herbarium, MO }\end{array}$ & 42 & 45 & $\begin{array}{l}\text { 美国密苏里州圣路易斯 } \\
\text { Saint Louis, Missouri, US }\end{array}$ \\
\hline 4 & $\begin{array}{l}\text { 中国科学院华南植物园标本馆 } \\
\text { South China Botanical Garden Herbarium, Chinese Academy of Sciences, IBSC }\end{array}$ & 33 & 38 & $\begin{array}{l}\text { 中国广东广州 } \\
\text { Guangzhou, Guangdong, China }\end{array}$ \\
\hline 5 & $\begin{array}{l}\text { 加州科学院植物标本馆 } \\
\text { The Botanical Collection at the California Academy of Sciences, CAS }\end{array}$ & 22 & 24 & $\begin{array}{l}\text { 美国加利福尼亚州旧金山 } \\
\text { San Francisco, California, US }\end{array}$ \\
\hline 6 & $\begin{array}{l}\text { 中国科学院植物研究所植物标本馆 } \\
\text { Herbarium, Institute of Botany, Chinese Academy of Sciences, PE }\end{array}$ & 20 & 37 & $\begin{array}{l}\text { 中国北京 } \\
\text { Beijing, China }\end{array}$ \\
\hline 7 & $\begin{array}{l}\text { 南京大学生物系植物标本室 } \\
\text { The Herbarium of Nanjing University, N }\end{array}$ & 11 & 14 & $\begin{array}{l}\text { 中国江苏南京 } \\
\text { Nanjing, Jiangsu, China }\end{array}$ \\
\hline 8 & $\begin{array}{l}\text { 邱园植物园植物标本馆 } \\
\text { Herbarium of the Royal Botanic Gardens, Kew, K }\end{array}$ & 10 & 11 & $\begin{array}{l}\text { 英国伦敦 } \\
\text { London, the United Kingdom }\end{array}$ \\
\hline 9 & $\begin{array}{l}\text { 英国自然历史博物馆植物标本馆 } \\
\text { Natural History Museum, London, UK, NHMUK }\end{array}$ & 7 & 11 & $\begin{array}{l}\text { 英国伦敦 } \\
\text { London, the United Kingdom }\end{array}$ \\
\hline 10 & $\begin{array}{l}\text { 毕夏普博物馆 } \\
\text { Bernice Pauahi Bishop Museum, BPBM }\end{array}$ & 7 & 7 & $\begin{array}{l}\text { 美国夏威夷州欧湖岛 } \\
\text { Oahu, Hawaii, US }\end{array}$ \\
\hline 11 & $\begin{array}{l}\text { 德克萨斯植物研究所植物标本馆 } \\
\text { Botanical Research Institute of Texas Herbarium, BRIT }\end{array}$ & 7 & 3 & $\begin{array}{l}\text { 美国德克萨斯州沃斯堡 } \\
\text { Fort Worth, Texas, US }\end{array}$ \\
\hline 12 & $\begin{array}{l}\text { 哈佛大学阿诺德树木园植物标本馆 } \\
\text { Herbarium of the Arnold Arboretum, Harvard University Herbaria, A }\end{array}$ & 5 & 6 & $\begin{array}{l}\text { 美国马萨诸塞州剑桥 } \\
\text { Cambridge, Massachusetts, US }\end{array}$ \\
\hline 13 & $\begin{array}{l}\text { 印第安纳大学植物标本馆 } \\
\text { Indiana University Herbarium, IND }\end{array}$ & 5 & 6 & $\begin{array}{l}\text { 美国印第安纳州布卢明顿 } \\
\text { Bloomington, Indiana, US }\end{array}$ \\
\hline 14 & $\begin{array}{l}\text { 澳大利亚国家植物标本馆 } \\
\text { Australian National Herbarium, CANB }\end{array}$ & 4 & 11 & $\begin{array}{l}\text { 澳大利亚堪培拉 } \\
\text { Canbera, Australia }\end{array}$ \\
\hline 15 & $\begin{array}{l}\text { 柏林-达勒姆植物园和植物博物馆植物标本馆 } \\
\text { Herbarium of the Botanic Garden and Botanical Museum Berlin-Dahlem, B }\end{array}$ & 4 & 4 & $\begin{array}{l}\text { 德国柏林 } \\
\text { Berlin, Germany }\end{array}$ \\
\hline 16 & $\begin{array}{l}\text { 哈佛大学格雷植物标本馆 } \\
\text { Gray Herbarium, Harvard University Herbaria, GH }\end{array}$ & 3 & 3 & $\begin{array}{l}\text { 美国马萨诸塞州剑桥 } \\
\text { Cambridge, Massachusetts, US }\end{array}$ \\
\hline 17 & $\begin{array}{l}\text { 卡内基博物馆植物标本馆 } \\
\text { Herbarium of Carnegie Museum, CM }\end{array}$ & 2 & 2 & $\begin{array}{l}\text { 美国宾夕法尼亚州匹兹堡 } \\
\text { Pittsburgh, Pennsylvania, US }\end{array}$ \\
\hline 18 & $\begin{array}{l}\text { 爱荷华州立大学艾达·海登植物标本馆 } \\
\text { Ada Hayden Herbarium, Iowa State University, ISC }\end{array}$ & 2 & 2 & $\begin{array}{l}\text { 美国爱荷华州埃姆斯 } \\
\text { Ames, Iowa, US }\end{array}$ \\
\hline 19 & $\begin{array}{l}\text { 纽约植物园植物标本馆 } \\
\text { William and Lynda Steere Herbarium of the New York Botanical Garden, NY }\end{array}$ & 1 & 1 & $\begin{array}{l}\text { 美国纽约州纽约 } \\
\text { New York, US }\end{array}$ \\
\hline 20 & $\begin{array}{l}\text { 北京大学生物系植物标本室 } \\
\text { Herbarium, Department of Biology, Peking University, PEY }\end{array}$ & 1 & 1 & $\begin{array}{l}\text { 中国北京 } \\
\text { Beijing, China }\end{array}$ \\
\hline
\end{tabular}


标注带来了困难(McClure, 1933); 由于地名拼写的 表达方式常夹杂方言, 在一定程度上存在拼写不规 范, 也使得地名考证较为困难。在确定准确地名过 程中, 还需要多方引证、查阅相关采集者档案等。 之后, 进一步考证我国行政区划变更因素, 更换成 我国最新地区行政区划地名。

\section{结果}

\section{1 采集时间}

收集到的2,238份竹类植物标本数据中, 记录 采集年份的有2,207份。我们对采集年份进行分析, 可将标本采集时间分为 3 个阶段：第一阶段 1840-1915年，第二阶段1916-1948年，第三阶段 1949-2010年，图1为各阶段标本量。

\subsection{1 第一阶段：竹类植物标本采集包含在全面植 物采集中}

在20世纪之前, 美国在华植物采集活动相对其 他国家较少, 标本数量不多。本研究查阅到的最早 的竹类植物采集记录是1853年赖特(Charles Wright,
1811-1885) 在香港采集了麻竹 (Dendrocalamus latiflorus)、水银竹(Indocalamus sinicus)等。进入20 世纪，美国农业部外国种子和植物引种办公室全面 开展引种工作，而阿诺德树木园一直热衷于对中国 植物开展研究, 此时中国国门也几乎被彻底打开, 于是美国农业部和阿诺德树木园等机构派出专业素 质过硬的采集者到中国开展大规模植物采集工作。

在这些机构派出“植物猎人”来华采集之前，他 们还通过在华的工作人员帮助采集和引种，如 1902-1908年，美国驻上海领事馆副总领事巴切特 (S. P. Barchet)博士为美国农业部采集植物，于1906 年在浙江金华采集毛金竹(Phyllostachys nigra var. henonis)、孝顺竹(Bambusa multiplex)等。

1906-1908年, 威尔逊为阿诺德树木园来华采 集植物期间采集过竹类植物标本，如1907-1908年 在湖北十堰房县和宜昌兴山县采集等。

梅耶前两次来华以引种植物为主要目的，萨金 特(Charles Sprague Sargent, 1841-1927)建议他重视 植物标本采集。梅耶在华第三次植物采集期间，于

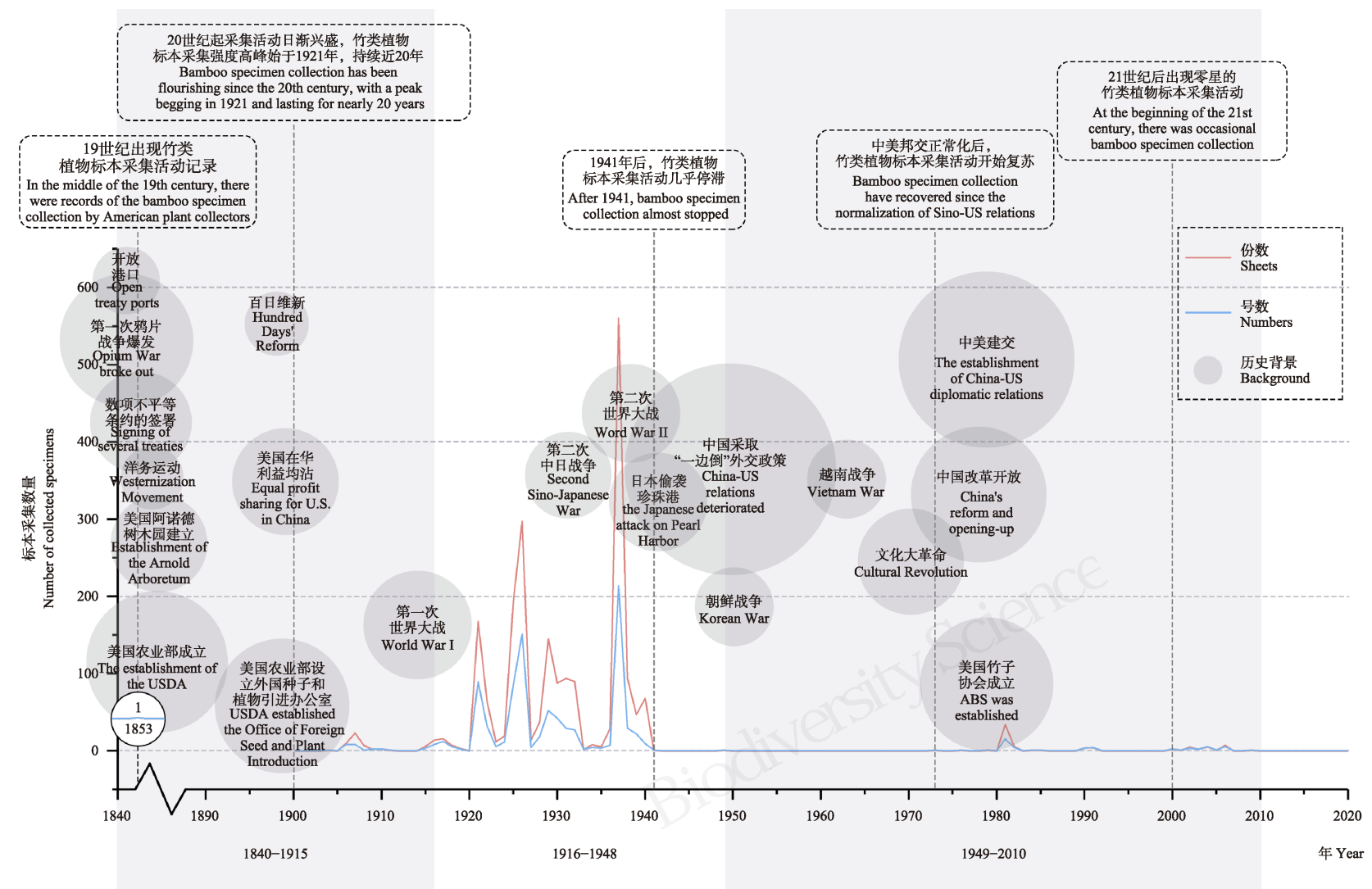

图1 美国在华采集竹类植物标本阶段

Fig. 1 The stages of the bamboo specimen collection in China by American plant collectors 
1915年来到浙江湖州市德清县莫干山采集毛竹 (Phyllostachys edulis)标本, 在杭州市临安区昌化镇 寻找山核桃 (Carya cathayensis) 时采集箬竹 (Indocalamus tessellatus)标本。

这一阶段的竹类植物标本采集包含在全面植 物采集中, 其标本采集总量不大, 采集时间主要集 中于20世纪初。1840-1915年, 美国在华共采集竹类 植物标本28号55份, 主要采集者是巴切特、威尔逊 和梅耶, 为美国在下一阶段派学者到中国研究、采 集和引种竹类植物打下了良好基础。

\subsection{2 第二阶段: 专门采集竹类植物标本并开展研究}

在中国抗日战争之前, 在华的农业传教士、学 者具有良好的工作研究环境, 在植物标本采集方面, 除有专门机构派出的采集者之外, 更多的是为了植 物学研究而开展的标本采集活动。

这一阶段, 在华教会学校的教师组织了全面的 植物标本采集, 并建立植物标本馆。与这一阶段竹 类植物标本采集和研究活动最为密切的事件是岭 南学校植物标本室的建设。1916年10月岭南学校植 物标本室成立, 由格罗夫(George Weidman Groff, 1884-1954)负责。在此之前, 学校还派出两名学生 去菲律宾马尼拉接受在菲律宾科学局工作的梅尔 (Elmer Drew Merrill, 1876-1956)的标本采集、制作 和管理方面的专门培训。梅尔长期在菲律宾开展太 平洋地区植物学调查和研究, 他非常愿意扶助中国 植物分类学成为一个独立发展的学科。1916年, 格 罗夫邀请到当时正在岭南学校考察的美国农业部 作物生理学家施温格和梅尔帮忙采集植物标本, 并 于当年10-11月开展采集工作, 标本由梅尔负责鉴 定和整理。在海珠区、罗浮山等地采集到吊丝球竹 (Bambusa beecheyana)、大头典竹(B. beecheyana var. pubescens)等代表性竹类植物标本。

由于格罗夫教学和行政事务繁忙。1917年, 标 本采集工作落在了畜牧系教师莱文身上。莱文和梅 尔在广东区域采集了标本室的最初一批标本, 其中 就包含部分竹类植物。

1921年开始, 莫古礼也开始了植物考察和标本 采集工作。1921年夏, 莫古礼同杜费平在汕头, 后 又同莱文在罗浮山采集。此后, 莫古礼又陪同专程 来华考察采集禾本科植物的美国国家标本馆系统 农业学家希区考克 (Albert Spear Hitchcock, 1865-1935)在广东、海南、香港等地采集竹类植物
标本。1921年10月下旬莫古礼在海南同杜费平采集, 于1922年4-6月再次前往海南采集。

1924年秋，莫古礼在美国学习和休假后再次回 到中国, 在美国农业部外国种子和植物引种办公室 的合作下, 在学校工作之外开展对中国植物的考察 和采集工作, 最初主要集中在广东、广西、海南等 地。1926年秋, 莫古礼开始对长江流域进行考察, 到过江苏、湖北、安徽, 最后经由江西返回到广东。 在这期间, 莫古礼认识到竹类植物是一个非常有应 用价值的类群, 但是由于其开花周期时间太长且不 定, 通过传统分类学的鉴定方法较难区分, 因此, 他除了采集腊叶标本之外还采集活植株到学校栽 培并观察，一直持续到1940年。

除岭南大学外, 同一时期的金陵大学也开展了 全面的植物采集工作。1922年, 梅尔组织金陵大学 教师采集标本; 1922-1925年, 金陵大学的植物学教 授史德蔚在中国多地采集过植物标本, 包括江苏南 京、江西庐山、安徽九华山、河南鸡公山。1931年, 史德蔚还带领学生到贵州采集植物标本。1933年, 南京大学与阿诺德树木园、纽约植物园建立合作关 系, 史德蔚和中国植物学家焦启源带领学生到广西 采集植物标本, 其中包括不少竹类植物标本。

1922年, 受雇于美国国家地理学会的洛克来华 进行植物采集和引种工作, 主要集中于云南区域, 采集的植物中包含竹类植物。

第二阶段是美国在华采集竹类植物标本最重 要的时期, 其主要目的是植物分类学研究, 如1916 年以岭南学院植物标本室建立为契机而开展的标 本采集, 尤其是1921年以后莫古礼专门从事竹类植 物的调查、采集和研究, 取得了前所未有的进展。 这个阶段的采集者有莱文、梅尔、希区考克、莫古 礼、洛克、麦克林(W. Macklin)、史德蔚和梅特卡夫 (Frank Post Metcalf, 1892-1955)等，共采集862号 2,076份竹类植物标本。

\subsection{3 第三阶段: 中美联合考察和采集竹类植物标本}

新中国成立初期, 来华考察、采集植物标本的 人员和组织机构较少。 20 世纪 70 年代开始, 中美关 系缓和, 美国陆续开始来华开展植物研究和采集工 作, 如1981年夏勒(G. Schaller)在汶川卧龙自然保护 区、塞登施蒂克(J. Seidensticker)在青川唐家河自然 保护区开展采集工作。从20世纪90年代到本世纪初, 中外陆续组织联合考察队开展生物多样性考察并 
进行植物标本采集, 如2002-2007年的美国国家科 学基金“中国云南西部热点地区高黎贡山生物多样 性调查” 项目, 组成了由中国科学院昆明植物研究 所、动物研究所、昆明动物研究所以及湖南师范大 学、美国加州科学院、英国爱丁堡皇家植物园和德 国马堡大学联合的植物学和昆虫学考察队 (Gaoligong Shan Biodiversity Survey), 陆续在高黎 贡山区域采集标本, 其中包含竹类植物标本。这一 阶段, 采集者们共采集52号77份竹类植物标本。

\section{2 采集种类}

在收集到的 2,238 份竹类植物标本中, 有 1,883 份已鉴定并标注学名。经学名校正后的接受名归属 于25属(占中国现有竹类植物属的73.5\%) 120种(含 变种、变型, 占中国竹种的 $22.5 \%$ ), 每属采集竹种数 量及中国各属竹种数量的对比见表2, 其中采集竹 种分布较多的为簕竹属 (Bambusa, 33种)、刚竹属 (Phyllostachys, 21种)和箭竹属(Fargesia, 7种), 这3 个属是我国竹类植物最常见的属, 分布广泛。

采集标本数量较多的属分别是簕竹属(289号 694份)、刚竹属(197号434份)和矢竹属(Pseudosasa, 94号252份) (表2)。有9种竹类采集标本超过50份, 采集最多的种分别是托竹(Pseudosasa cantorii， 61 号137份)、桂竹(Phyllostachys reticulata, 48号109份) 以及青秆竹(Bambusa tuldoides, 36号87份)。有48种 标本数量超过 10 份, 占比 $39.7 \%$, 但也有 14 种只存 有1份标本(详见附录1)。采集数量多的种类通常占 据较广的分布区, 因此在竹类植物研究之初更容易 被采集者所关注。

\section{3 采集地}

获取的标本数据中, 共计 2,217 份能够判定出 采集省份, 采集地涉及20个省、自治区、直辖市和 特别行政区, 图2展示了采集分布及各省采集标本 号数和份数。采集标本份数超过 50 的省、自治区及 特别行政区等有 8 个, 包括广东 $(1,029$ 份)、香港(402 份)、海南(216份)、广西(130份)、安徽(94份)、福建 (66份)、江西(54份)以及云南(50份)。有1,800份能够 判定出采集的地级市, 涉及到的市、自治州有65个, 共 82 个区(县以及县级市)。采集标本份数最多的城 市为: 广州(674份)、桂林(100份)、肇庆(89份)、清 远(85份)、儋州(67份)、池州(57份)以及韶关(54份), 图2各省平面图列出了各城市采集强度。

采集数量最多的区域是华南, 这是由于莫古礼
的研究范围主要在华南, 尤其是广东。莫古礼除采 集野外标本外, 对种植到岭南大学竹园的竹类也会 采集标本。此外, 梅尔、希区考克以及莱文在华的 考察采集范围也集中在华南, 莫古礼、希区考克等 在广州、清远市英德市、韶关等地采集过程中还拍 摄了采集地概况。华东区域的采集者主要是巴切 特、梅耶和史德蔚。在华东区域有大量人工栽培的 散生竹, 采集者更多是在人工栽培环境下考察和采 集竹类, 如梅耶在南京发现人们将竹类种植在菜园 中, 方便采笋(http://id.lib.harvard.edu/images/olvwor rk283628/catalog)。在湖州德清莫干山附近, 人工栽 培竹林基本是在房前屋后的小山坡上(http://id.lib.h arvard.edu/images/olvwork283618/catalog), 竹、山核 桃、茶叶是杭州临安区的特产, 梅耶的2张照片就显 示了竹类与其他特色植物的组合(http://id.lib.harvar d.edu/images/olvwork282674/catalog; http://id.lib.har vard.edu/images/olvwork283636/catalog)。新中国成 立以前, 在西南采集标本的主要为威尔逊和洛克。 湖北西部及四川、云南等地的采集地偏自然生境, 如威尔逊在宜昌(http://id.lib.harvard.edu/images/olv work291143/catalog)、甘孜藏族自治州康定市 (http://id.lib.harvard.edu/images/olvwork288045/catal og)、眉山市洪雅县(http://id.lib.harvard.edu/images/ olvwork289056/catalog)的考察地均是自然山林, 少 量为人工种植环境, 如成都平原老百姓自种的竹 (http://id.lib.harvard.edu/images/olvwork289175/catal og)。1980年之后, 采集地主要分布在西南, 采集者 为夏勒、塞登施蒂克。很显然, 采集地几乎覆盖中 国竹类植物的自然分布地, 主要集中在华南、华东 和西南。

\section{4 采集者}

统计分析发现, 美国来华采集竹类植物的共计 有 45 个采集者和采集队。表3列出了各采集者及其 标本采集数量, 在众多采集者中, 以开展研究为目 的的教会学校在标本采集数量上尤为突出, 如岭南 大学的莫古礼和莱文, 金陵大学的史德蔚、希区考 克等。

莫古礼1919年大学毕业后接受了中国广州岭 南学校任教的工作, 从此开始了在中国开展竹子研 究的生涯, 一直到1940年底。莫古礼对竹子研究的 影响极其深远, 极大地发展了竹子分类学。回到美 国后, 莫古礼继续开展竹子的研究, 在中国研究竹 
类植物的基础上所著的 The Bamboos-A Fresh Perspective中有对分类基础的专述, 及不同属的种 子所表现的开花和结果的形状, 尤其是无限花序与 有限花序的理论，在当时具有独创性。

希区考克是美国著名的植物学家, 开创了用模 式标本进行植物命名的方法。他于1901年进入美国 农业部工作, 主要研究禾本科植物, 并有了全球考 察的机会, 中国是他的一个主要考察地。希区考克还 是我国著名植物学家耿以礼(1897-1975)在美国史密 森研究院(Smithsonian Institution)学习期间的导师。

\section{3 美国在华采集竹类植物标本的意义}

3.1 增加对竹类植物应用价值的认识

美国采集者研究和采集中国竹类植物的一个
直接结果就是认识到中国竹类植物种类丰富, 并具 有极高的观赏价值和经济用途(McClure，1931; Young \& Haun, 1961)。美国自然分布的竹类植物仅 青篱竹属(Arundinaria)的3种, 分别为Arundinaria appalachiana、A. gigantea和 $A$. tecta (Triplett et al, 2006; Triplett \& Clark, 2009; Krayesky \& Chmielewski, 2014)。在来华采集之前, 他们认为北 美分布的竹类植物形态小，呈藤状，利用价值不高 (Galloway, 1928)。我国竹类植物高度和形态各不相 同，具有不同用途，引起了采集者的注意。梅耶认 为毛竹高大，是中国 “最大”的竹类植物，其竹竿不 仅具有多种用途，并且毛竹林具有很好的观赏价值 (http://id.lib.harvard.edu/images/olvwork279830/catal og; http://id.lib.harvard.edu/images/olvwork280452/ca

表2 美国来华采集每属竹种数量与中国各属竹种数量的对比以及各属标本数量(中国竹类植物数据来源: Flora of China第 22卷)

Table 2 Comparison of the number of bamboo species of each genus collected in China with the number of bamboo species of each genus in China and the number of bamboo specimens of each genus collected by American plant collectors (Data source of bamboo species in China: Flora of China (Vol. 22))

\begin{tabular}{|c|c|c|c|c|c|}
\hline 序号 & No. 属名 Genus name & 中国种数 No. of species in China & 采集种数 No. of collected species & 号数 Numbers & 份数 Sheets \\
\hline 1 & 簕竹属 Bambusa & 80 & 32 & 289 & 694 \\
\hline 2 & 刚竹属 Phyllostachys & 51 & 21 & 197 & 434 \\
\hline 3 & 箭竹属 Fargesia & 78 & 7 & 15 & 28 \\
\hline 4 & 箅筫竹属 Schizostachyum & 15 & 6 & 27 & 95 \\
\hline 5 & 牡竹属 Dendrocalamus & 27 & 6 & 34 & 78 \\
\hline 6 & 箬竹属 Indocalamus & 22 & 5 & 30 & 88 \\
\hline 7 & 唐竹属 Sinobambusa & 10 & 5 & 14 & 28 \\
\hline 8 & 苦竹属 Pleioblastus & 17 & 5 & 12 & 20 \\
\hline 9 & 矢竹属 Pseudosasa & 18 & 4 & 94 & 252 \\
\hline 10 & 少穗竹属 Oligostachyum & 15 & 3 & 9 & 45 \\
\hline 11 & 青篱竹属 Arundinaria & 5 & 3 & 11 & 29 \\
\hline 12 & 方竹属 Chimonobambusa & 34 & 3 & 5 & 14 \\
\hline 13 & 藤竹属 Dinochloa & 4 & 3 & 3 & 12 \\
\hline 14 & 酸竹属 Acidosasa & 10 & 2 & 6 & 17 \\
\hline 15 & 大节竹属 Indosasa & 15 & 2 & 6 & 10 \\
\hline 16 & 赤竹属 Sasa & 8 & 2 & 4 & 10 \\
\hline 17 & 玉山竹属 Yushania & 58 & 2 & 3 & 9 \\
\hline 18 & 巨竹属 Gigantochloa & 6 & 2 & 2 & 6 \\
\hline 19 & 空竹属 Cephalostachyum & 6 & 1 & 1 & 4 \\
\hline 20 & 悬竹属 Ampelocalamus & 13 & 1 & 1 & 2 \\
\hline 21 & 贡山竹属 Gaoligongshania & 1 & 1 & 2 & 2 \\
\hline 22 & 梨竹属 Melocanna & 1 & 1 & 1 & 2 \\
\hline 23 & 业平竹属 Semiarundinaria & 3 & 1 & 2 & 2 \\
\hline 24 & 单枝竹属 Bonia & 4 & 1 & 1 & 1 \\
\hline 25 & 我鸟毛竹属 Shibataea & 10 & 1 & 1 & 1 \\
\hline
\end{tabular}




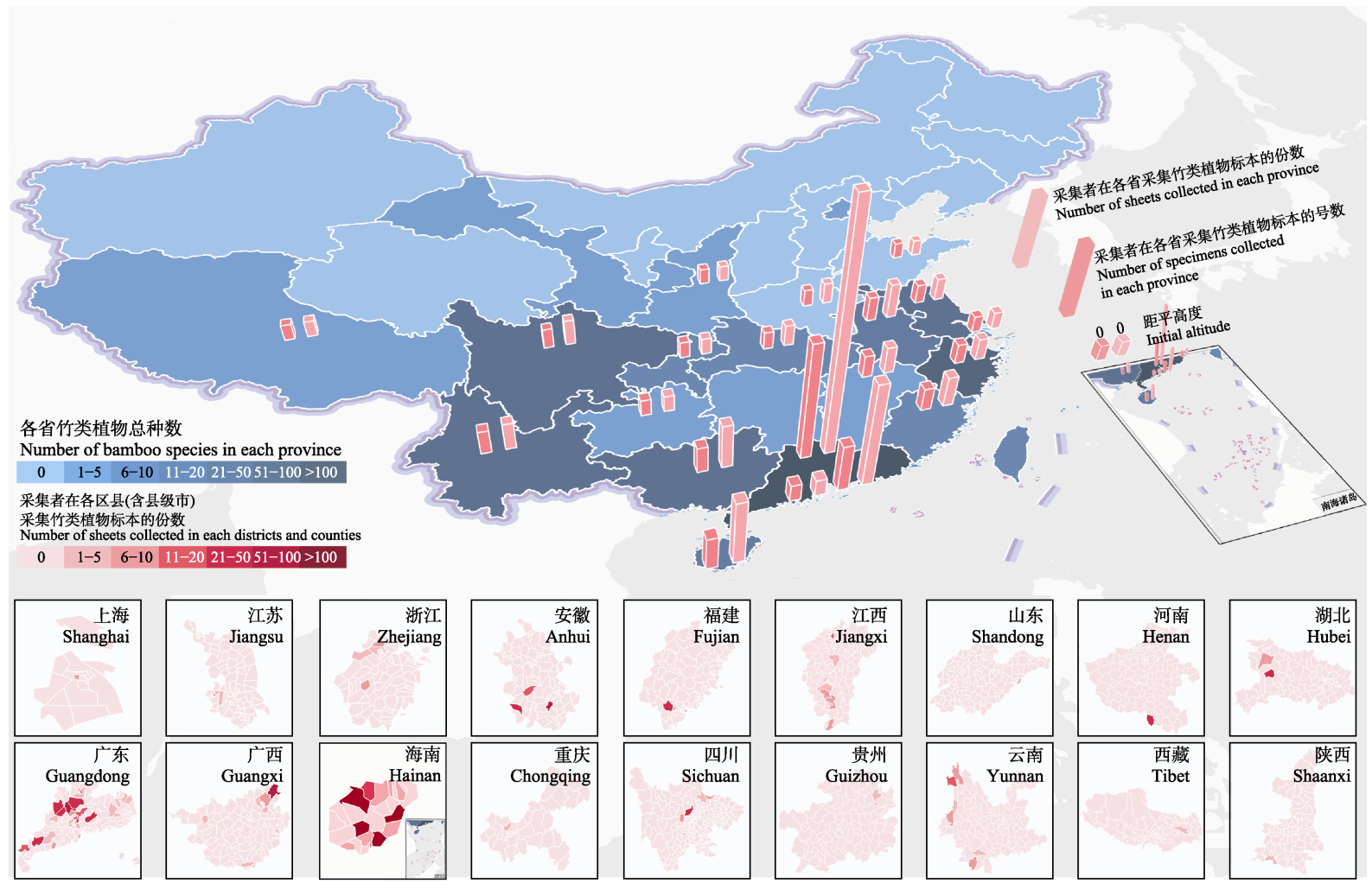

图2 美国来华采集竹类植物标本采集地分布

Fig. 2 The distribution of bamboo collection places in China by American plant collectors

talog); 威尔逊考察过吊丝球竹和毛竹组合的景观 效果(http://id.lib.harvard.edu/images/olvwork289439/ catalog)。灌木状竹类植物还可以与裸子植物组合, 如威尔逊在湖北十堰房县拍摄的巴山冷杉(Abies fargesii)和神农箭竹(Fargesia murielae) (http://id.lib. harvard.edu/images/olvwork292740/catalog), 这种组 合在现今美国公园绿地中也常被借鉴使用。从生竹 蔓延能力较弱, 莫古礼观察到有用孝顺竹制作成为 绿篱。此外, 采集者们还观察到建筑与竹类植物结 合的景观效果也非常好, 如威尔逊在四川成都都江 堰观察到在一座寺庙周边种满竹类植物 (http://id.lib.harvard.edu/images/olvwork177705/cata $\log )$ 。竹类植物还具有极高的经济价值, 梅耶看到竹 竿以水运方式运送到不同地方加以利用(http://id.lib. harvard.edu/images/olvwork280455/catalog); 在上海 虹桥的集市上看到可食用的竹笋(http://id.lib.harvar d.edu/images/olvwork279845/catalog); 在浙江看到 河边的竹栅栏(http://id.lib.harvard.edu/images/olvwo rk279829/catalog); 还有制成半成品的竹䉝(http://id. lib.harvard.edu/images/olvwork282715/catalog)。除此 之外, 竹浆造纸也是竹类植物的一大用途。这些用
途为他们引种竹类植物到美国提供了借鉴。

\section{2 加快竹子分类学研究}

竹类植物开花不多见, 结实则更少, 难以利用 有性器官进行分类, 而且种间形态差异小、受出笋 的季节性限制等，使得其在分类上存在一定难度， 这也就使得竹类植物研究的突出问题始终表现在 分类学研究方面(方伟, 1995)。鉴于此, 竹子分类学 多运用营养体中比较稳定的特征来辅助分类(郑蓉 等, 2006)。中国在古代已对竹类植物有过分类研究, 竹类专著有晋朝戴凯之的《竹谱》、元朝李衍的《竹 谱详录》等, 对竹类植物的系统分类则始于 19 世纪 初, 最早用近代植物分类方法命名的中国竹类是德 国植物学家韦尔登诺(Carl Ludwig Willdenow)于 1808年发表的孝顺竹(Ludolfia glaucescens), 到1868 年, 芒罗(Colonel Munro)发表的第一部世界性竹类 专著A Monograph of the Bambusaceae中记载了中国 竹类植物5属22种(William, 1868)。

对中国竹类植物进行系统研究的首推莫古礼 (赵奇僧和汤庚国, 1993)。在中国研究期间, 莫古礼 共发表了 74 个新种、 9 个变种、 8 个新组合以及 3 个 新属(McClure, 1931, 1935, 1936, 1938, 1940a, b, c, 
表3 美国来华竹类植物的采集者及其采集标本数量

Table 3 The American bamboo collectors in China and the number of specimens collected

\begin{tabular}{|c|c|c|c|c|c|c|c|}
\hline $\begin{array}{l}\text { 序号 } \\
\text { No. }\end{array}$ & $\begin{array}{l}\text { 采集者 } \\
\text { Collector }\end{array}$ & $\begin{array}{l}\text { 份数 } \\
\text { Sheets }\end{array}$ & $\begin{array}{l}\text { 号数 } \\
\text { Number }\end{array}$ & 序号 & $\begin{array}{l}\text { 采集者 } \\
\text { Collector }\end{array}$ & $\begin{array}{l}\text { 份数 } \\
\text { Sheets }\end{array}$ & $\begin{array}{l}\text { 号数 } \\
\text { Number }\end{array}$ \\
\hline 1 & 莫古礼 F. A. McClure & 1,840 & 727 & 24 & 内贝尔 O. Nebel & 2 & 2 \\
\hline 2 & 希区考克 A. S. Hitchcock & 117 & 62 & 25 & 塞登施迪克 T. R. Soderstrom & 2 & 2 \\
\hline 3 & 莱文 C. O. Levine & 28 & 19 & 26 & 亨德森 M. Henderson & 5 & 1 \\
\hline 4 & 史德蔚 A. N. Steward & 29 & 18 & 27 & 莫克 R. Mok & 3 & 1 \\
\hline 5 & 夏勒 G. Schaller & 21 & 11 & 28 & 沃、谢尔曼 J. Woo and R. Sherman & 2 & 1 \\
\hline 6 & 梅尔E. D. Merrill & 14 & 11 & 29 & 肯尼迪 A. Kennedy & 1 & 1 \\
\hline 7 & $\begin{array}{l}\text { 高黎贡山生物多样性考察队 } \\
\text { Gaoligong Shan Biodiversity Survey }\end{array}$ & 13 & 10 & 30 & 罗宾逊 C. B. Robinson & 1 & 1 \\
\hline 8 & 威尔逊 E. H. Wilson ${ }^{*}$ & 30 & 9 & 31 & $\begin{array}{l}\text { 安德森、萨里克、冈恩 } \\
\text { D. M. Anderson, J. Salick, B. F. Gunn, X. Yin, N. An }\end{array}$ & 1 & 1 \\
\hline 9 & 洛克 J. F. Rock & 20 & 9 & 32 & $\begin{array}{l}\text { 安德森、萨里克、冈恩 } \\
\text { D. M. Anderson, J. Salick, B. F. Gunn, X. Yin, }\end{array}$ & 1 & 1 \\
\hline 10 & 德沃尔 C. E. Devol & 10 & 8 & 33 & 维图 E. Vitou & 1 & 1 \\
\hline 11 & 巴切特 S. P. Barchet & 10 & 8 & 34 & 桂林考察团 Guilin Expedition & 1 & 1 \\
\hline 12 & $\begin{array}{l}\text { 独龙江考察团 } \\
\text { Dulong Jiang Investigation Team }\end{array}$ & 8 & 7 & 35 & $\begin{array}{l}\text { 布鲁斯、菲利普、弗里奇 } \\
\text { H. Li, B. Bruce, T. Philippe, P. Fritsch, Z. Dao, Z. } \\
\text { Wang, R. Li }\end{array}$ & 1 & 1 \\
\hline 13 & 赛登施蒂克 J. Seidensticker & 17 & 6 & 36 & 摩尔斯 H. Morse & 1 & 1 \\
\hline 14 & 阿杜 A. To & 8 & 6 & 37 & 威尔雅 H. Wawra & 1 & 1 \\
\hline 15 & 梅特卡夫 F. P. Metcalf & 8 & 5 & 38 & 坎贝尔 J. E. Campbell & 1 & 1 \\
\hline 16 & 威尔逊 W. F. Wilson & 7 & 3 & 39 & $\begin{array}{l}\text { 麦克阿瑟、卢茨 } \\
\text { J. MacArthur, Z. Wen, L. Nie, Y. Xie, G. Niu, F. Li, } \\
\text { S. Yang, Lutz, J. Van De Veire }\end{array}$ & 1 & 1 \\
\hline 17 & 梅耶 F. N. Meyer & 6 & 3 & 40 & 沃、谢尔曼、萨里克 J. Woo, R. Sherman, Jan Salick & & 1 \\
\hline 18 & 麦克林 W. Macklin & 7 & 3 & 41 & 比奇 K. H. Beach & 1 & 1 \\
\hline 19 & 赖特 C. Wright & 3 & 3 & 42 & $\begin{array}{l}\text { 吉尔伯特、蒂兰 M. G. Gilbert, Y. F. Deng, Z. Li, N. } \\
\text { J. Turland, Y. Sun, N. H. Xia, Y. L. Zheng }\end{array}$ & & 1 \\
\hline 20 & 邓恩 Dunn & 3 & 2 & 43 & 哈雷 M. Halle & 1 & 1 \\
\hline 21 & 雷威、杜克 J. L. Reveal, J. A. Duke & 3 & 2 & 44 & $\begin{array}{l}\text { 卡普 Ma Man Kaap (Under the direction of G. W. } \\
\text { Groff) }\end{array}$ & 1 & 1 \\
\hline 22 & 萨里克 J. Salick & 3 & 2 & 45 & 熊猫调查团 Panda Survey Group & 1 & 1 \\
\hline 23 & $\begin{array}{l}\text { 霍夫迈斯特、阿门德 } \\
\text { K. Hoffmeister, Z. Deng, A. Amend }\end{array}$ & 2 & 2 & & & & \\
\hline
\end{tabular}

* 正文中的威尔逊均指此人。 $*$ The Wilson in this paper was him.

1941), 这大大促进了中国竹子分类学的发展。莫古 礼发表新属新种时慎重的研究方法是非常可取的: 他先把野外发现的竹类引种到竹园栽培, 仔细观察 其形态特征, 然后再确定是否是新属新种。20世纪 70年代开始编撰的《中国植物志》, 竹亚科由耿伯 介、王正平等负责, 他们对中国竹类植物进行了大 规模调查和标本采集, 同时也参考了莫古礼此前在 华采集的竹类标本和相关研究成果。可惜的是, 莫 古礼及其同事当时在华采集的竹类植物标本(包含 模式标本)一半被运到美国, 这些标本现在保存于 美国自然历史博物馆植物标本馆, 对植物志的编写 带来一定的不便, 所幸还有当时拍的标本照片可以 参考。

\section{3 促进美国在华引种竹类植物}

在19世纪, 美国很少以研究植物为目的在中国
开展植物考察和采集。到20世纪, 美国在华的植物 考察和标本采集与其来华植物引种密切相关。这些 植物标本极大地帮助了美国植物引种以及后续的 栽培和研究。如梅耶共引种37份(6属24种)竹类植物, 毛环竹(Phyllostachys meyeri)种加词meyeri就是为了 纪念梅耶为美国引种所做出的巨大贡献。威尔逊在 第3次(1907-1908年)来华考察时到达湖北和四川并 被竹类植物所吸引, 共采集8份(6属8种)竹类植物标 本, 而箭竹属植物是威尔逊引种最为成功的一类。 在中国研究期间, 莫古礼一共向美国引种255份竹 类植物, 包括18属81种(含变种、变型) ( Wu et al, 2020)。

竹类植物标本采集历史表明, 美国采集者在中 国采集竹类植物标本量大, 增加了对中国竹类植物 的认识, 加快了竹子分类学的研究并促进了美国在 
中国引种竹类植物。本研究的年份跨度约170年, 标 本采集也受到中国和世界历史背景的影响。经鉴定 美国来华采集的竹类植物属于 25 属(占中国属的 73.5\%) 120种(含变种、变型，占中国属的22.5\%)。 采集地涉及到20个省级行政区、67个市级行政区、 82个区县, 几乎覆盖了我国竹类植物的所有自然分 布区域。共有45位(支)采集者(采集队)在华采集过竹 类植物标本, 其中莫古礼贡献卓著。在今后的研究 中, 我们可继续对欧美等国在华采集和引种植物的 历史开展研究, 同时我国在其他地区引种的历史也 值得关注。植物采集和引种史研究的成果最终可服 务于今后国内外的植物引种和社会发展, 开展更广 泛的全球引种工作, 如从现在主要在亚洲引种拓展 到植物资源丰富的南美洲、大洋洲和非洲。还要开 展植物引种后的相关适应性和应用研究, 加强植物 资源的保护、挖掘、收藏和利用, 实现我国植物资 源大国到植物资源强国的根本转变。

\section{ORCID}

吴仁武 (D) https://orcid.org/0000-0002-0036-2947

南歆格 (i) https://orcid.org/0000-0003-2482-7961

晏海 (D) https://orcid.org/0000-0003-1326-5254

杨凡 (iD https://orcid.org/0000-0003-0275-5071

史琰 (iD https://orcid.org/0000-0001-6140-9748

包志毅 (D) https://orcid.org/0000-0003-2155-1824

\section{参考文献}

Bretschneider EV (1871) On the Study and Value of Chinese Botanical Works, with Notes on the History of Plants and Geographical Botany from Chinese Sources. Rozario, Marcal \& Company, Fuzhou.

Bretschneider EV (1898) History of European Botanical Discoveries in China. Sampson Low, Marston \& Company, London.

Cox EHM (1945) Plant-Hunting in China: A History of Botanical Exploration in China and the Tibetan Marches. Collins Clear-Type Press, London \& Glasgow.

Cunningham IS (1984) Frank Meyer, Agricultural explore. Arnoldia, 44(3), 3-26.

Fairchild DG (1903) Japanese Bamboos and Their Introduction into America. United States Department of Agriculture (Bulletin No. 43), Washington, DC.

Fan F (2004) British Naturalists in Qing China: Science, Empire and Cultural Encounter. Harvard University Press, Cambridge.

Fang W (1995) Bambuseae Taxonomy. China Forestry Publishing House, Beijing. (in Chinese) [方伟 (1995) 竹子分类学. 中国 林业出版社, 北京.]

Galloway BT (1928) Bamboos and Bamboo Culture. United States Department of Agriculture (Leaflet No. 18), Washington, DC.
Galloway BT (1925) Bamboos: Their culture and used in the United States. In: United States Department of Agriculture (Bulletin No. 1329), Washington, D. C.

Keng PC, Wang ZP (1996) Flora Reipublicae Popularis Sinicae, Tomus 9. Science Press, Beijing. (in Chinese) [耿伯介, 王正平 (1996) 中国植物志(第九卷). 科学出版社, 北京.]

Krayesky DM, Chmielewski JG (2014) Arundinaria gigantea: New to Pennsylvania. Rhodora, 116, 228-231

Li HL (1959) The Garden Flowers of China. The Ronald Press Company, New York.

Lin W, Chen QB, Jiang MY, Zhang XX, Liu ZF, Tao JY, Wu LJ, Xu S, Kang YS, Zeng QY (2019) The effect of green space behaviour and per capita area in small urban green spaces on psychophysiological responses. Landscape and Urban Planning, 192, 103637.

Luo GH (1994) Botanical expeditions and collections made by westerners in China since the Qing Dynasty. China Historical Materials of Science and Technology, 15(2), 17-31. (in Chinese with English abstract) [罗桂环 (1994) 近代西方人在华的植 物学考察和收集. 中国科技史料, 15(2), 17-31.]

Luo GH (2005) History of Western Botanical and Zoological Studies in China. Shandong Education Press, Jinan. (in Chinese) [罗桂环 (2005) 近代西方识华生物史. 山东教育出版社, 济 南.]

Ma JS (2011) The Outline of Taxonomy Literature of Eastern Asian Higher Plants. Higher Education Press, Beijing. (in Chinese) [马金双 (2011) 东亚高等植物分类学文献概览. 高 等教育出版社, 北京.]

Ma JS (2014) Current status and challenges of Chinese plant taxonomy. Chinese Science Bulletin, 59, 510521. (in Chinese with English abstract) [马金双 (2014) 中国植物分类学的现 状与挑战. 科学通报, 59, 510-521.]

Ma JS, Hu, ZG Liao S, Ye W, Boufford DE (2020) A Chronicle of Plant Taxonomy of China. Henan Science and Technology Press, Zhengzhou. [马金双, 胡宗刚, 廖帅, 叶文, 鲍棣伟 (2020) 中国植物分类学纪事. 河南科学技术出版社, 郑州.]

Maden K (2004) Plant collection and herbarium techniques. Our Nature, 2(1), 53-57.

McClure FA (1931) Studies of Chinese bamboos. A new species of Arundinaria from southern China. Lingnan Science Journal, 10, 5-10.

McClure FA (1933) Outline maps of Kwangtung Povince and Hainan Island with notes on the names of the districts and district cities. Lingnan Science Journal, 12, 367-380.

McClure FA (1935) The Chinese species of Schizostachyum. Lingnan Science Journal, 14, 575-602.

McClure FA (1936) Two new species of Bambusa from southeastern China (Gramineae). Lingnan Science Journal, 15, 637-643.

McClure FA (1938) Bambusa ventricosa, a new species with a teratological bent. Lingnan Science Journal, 17, 57-61.

McClure FA (1940a) Five new bamboos from southern China. Lingnan Science Journal, 19, 531-542.

McClure FA (1940b) New genera and species of Bambusaceae from eastern Asia. Lingnan University Science Bulletin, 9, 
$1-67$.

McClure FA (1940c) Two new thorny species of Bambusa from southern China. Lingnan Science Journal, 19, 411-415.

McClure FA (1941) On some new and imperfectly known species of Chinese bamboos. Sunyatsenia, 6, 28-51.

McClure FA (1956) Bamboo in the economy of oriental peoples. Economic Botany, 10, 335-361.

McClure FA (1966) The Bamboos, A Fresh Perspective. Harvard University Press, Boston.

Meyer FG (1972) Floyd Alonzo McClure (1897-1970) —A tribute. Economic Botany, 26, 1-12.

Ohrnberger D (1999) The bamboos of the world: Annotated Nomenclature and Literature of the Species and the Higher and Lower Taxa. Elsevier, Online.

Rydin Y, Bleahu A, Davies M, Dávila JD, Friel S, De Grandis G, Groce N, Hallal PC, Hamilton I, Howden-Chapman P, Lai KM, Lim CJ, Martins J, Osrin D, Ridley I, Scott I, Taylor M, Wilkinson P, Wilson J (2012) Shaping cities for health: Complexity and the planning of urban environments in the 21st century. The Lancet, 379, 2079-2108.

Ryerson KA (1933) History and significance of the foreign plant introduction work of the United States Department of Agriculture. Agricultural History, 7(3), 110-128.

Smith WW (1930) The contribution of China to European Gardens. The Fifth International Botanical Congress, Cambridge, Massachusetts.

Stoner A, Hummer K (2007) 19th and 20th century plant hunters. HortScience, 42, 197-199.

Su XH (1987) The history of introduction of Chinese plant germplasm resources and use in English garden. Acta Horticulturae Sinica, 14(2), 133-138. (in Chinese with English abstract) [苏雪痕 (1987) 英国引种中国园林植物种质资源史 实及应用概况. 园艺学报, 14(2), 133-138.]

Swingle WT (1900) The origin of the flora of eastern Asia, a reservoir of useful plants. European Journal of Ophthalmology, 17, 1902-1903.

Triplett JK, Clark LG (2009) Towards a stable nomenclature for the North American temperate bamboos: Epitypification of Arundo gigantea Walt. and Arundinaria macrosperma Michx. (Poaceae). Castanea, 74, 207-212.

Triplett JK, Clark LG, Weakley AS (2006) Hill cane (Arundinaria appalachiana), a new species of bamboo (Poaceae: Bambusoideae) from the southern Appalachian Mountains. SIDA, 22, 79-95.

Veitch JH (1906) Hortus Veitchii, A History of the Rise and Progress of the Nurseries of Messrs. James Veitch and Sons. Cambridge University Press, London.

William MA (1868) A Monograph of the Bambusaceae, including
Descriptions of all the Species. Transactions of the Linnean Society of London, 26, 1-157.

Wilson EH (1913) A Naturalist in Western China with Vasculum, Camera and Gun. Vol. 1. Methuen \& Co. Ltd., London.

Wilson EH (1929) China, Mother of Gardens. The Stratford Company, Boston.

World Health Organization (2016) Global Report on Urban Health: Equitable, Healthier Cities for Sustainable Development. World Health Organization, Switzerland.

Wu RW, Nan XG, Yan H, Yang F, Shi Y, Bao ZY (2020) A survey on the history of the introduction of bamboo from China to the United States (1898-2010) and the application of bamboo in urban greening. Urban Forestry \& Urban Greening, 55, 126792.

Wu, ZY, Raven PH, Hong DY (2006) Flora of China, Vol. 22, Poaceae. Science Press, Beijing.

Young RA, Haun JR (1961) Bamboo in the United States: Description, Culture, and Utilization. U. S. Department of Agriculture Handbook No. 193.

Yu DJ (1962) The contribution of Chinese plants to world horticulture. Acta Horticulturae Sinica, (2), 99-108. (in Chinese) [俞德浚 (1962) 中国植物对世界园艺的贡献. 园艺 学报, (2), 99-108.]

Zhao QS, Tang GG (1993) The present status and problems of bamboo classification in China. Journal of Nanjing Forestry University (Natural Science), 17(4), 48. (in Chinese with English abstract) [赵奇僧, 汤庚国 (1993) 中国竹子分类的现 状和问题. 南京林业大学学报(自然科学版), 17(4), 1-8.]

Zhao TQ (1991a) Investigation of Biological Resources of Foreigners in Modern China. Bulletin of Biology, 26(7), 33-34, 28. (in Chinese) [赵铁桥 (1991a) 近代外国人在中国的生物 资源考察. 生物学通报, 26(7), 33-34, 28.]

Zhao TQ (1991b) Investigation of Biological Resources of Foreigners in Modern China (Continued). Bulletin of Biology, 26(8), 28-30. (in Chinese) [赵铁桥 (1991b) 近代外国人在中 国的生物资源考察(续). 生物学通报, 26(8), 28-30.]

Zheng R, Zheng WP, Fang W (2006) Application of DNA molecular markers in studying bamboo toxonomy. Journal of Fujian Forestry Science and Technology, 33(3), 161-165. (in Chinese with English abstract) [郑蓉, 郑维鹏, 方伟 (2006) DNA分子标记在竹子分类研究中的应用. 福建林业科技. 33(3), 161-165.]

Zhu ZX, Roeder M, Xie J, Nizamani MM, Friedman CR, Wang HF (2019) Plant taxonomic richness and phylogenetic diversity across different cities in China. Urban Forestry \& Urban Greening, 39, 55-66.

\section{附录 Supplementary Material}

\section{附录1 美国在华采集竹类植物标本名录}

Appendix 1 The list of bamboo specimen collected by American plant collectors in China http://www.biodiversity-science.net/fileup/PDF/2021029-1.pdf 
吴仁武, 南歆格, 晏海, 杨凡, 史琰, 包志毅 (2021) 美国在华采集竹类植物标本的历史(1840-2010 年). 生

物多样性, 29, 960-970. http://www.biodiversity-science.net/CN/10.17520/biods.2021029

附录1 美国在华采集竹类植物标本名录

Appendix 1 The list of bamboo specimen collected by American plant collectors in China

\begin{tabular}{|c|c|c|c|c|}
\hline 序号 No. & 属 Genus & 物种 Species & 号数 Numbers & 份数 Sheets \\
\hline 1 & 酸竹属 Acidosasa & 长舌酸竹 Acidosasa nanunica & 3 & 6 \\
\hline 2 & 酸竹属 Acidosasa & 黎竹 Acidosasa venusta & 3 & 11 \\
\hline 3 & 悬竹属 Ampelocalamus & 射毛悬竹 Ampelocalamus actinotrichus & 1 & 2 \\
\hline 4 & 青篱竹属 Arundinaria & 冷箭竹 Arundinaria faberi & 9 & 18 \\
\hline 5 & 青篱竹属 Arundinaria & 巴山木竹 Arundinaria fargesii & 1 & 10 \\
\hline 6 & 青篱竹属 Arundinaria & 总花冷箭竹 Arundinaria racemosa & 1 & 1 \\
\hline 7 & 簕竹属 Bambusa & 印度簕竹 Bambusa bambos & 15 & 25 \\
\hline 8 & 簕竹属 Bambusa & 吊丝球竹 Bambusa beecheyana & 25 & 71 \\
\hline 9 & 簕竹属 Bambusa & 大头典竹 Bambusa beecheyana var. pubescens & 10 & 21 \\
\hline 10 & 簕竹属 Bambusa & 簕竹 Bambusa blumeana & 24 & 51 \\
\hline 11 & 簕竹属 Bambusa & 箪竹 Bambusa cerosissima & 4 & 18 \\
\hline 12 & 簕竹属 Bambusa & 粉箪竹 Bambusa chungii & 6 & 25 \\
\hline 13 & 簕竹属 Bambusa & 牛角竹 Bambusa cornigera & 2 & 3 \\
\hline 14 & 簕竹属 Bambusa & 坭簕竹 Bambusa dissimulator & 9 & 25 \\
\hline 15 & 簕竹属 Bambusa & 白节簕竹 Bambusa dissimulator var. albinodia & 2 & 5 \\
\hline 16 & 簕竹属 Bambusa & 毛簕竹 Bambusa dissimulator var. hispida & 2 & 9 \\
\hline 17 & 簕竹属 Bambusa & 长枝竹 Bambusa dolichoclada & 3 & 7 \\
\hline 18 & 簕竹属 Bambusa & 慈竹 Bambusa emeiensis & 5 & 17 \\
\hline 19 & 簕竹属 Bambusa & 大眼竹 Bambusa eutuldoides & 10 & 16 \\
\hline 20 & 簕竹属 Bambusa & 银丝大眼竹 Bambusa eutuldoides var. basistriata & 1 & 2 \\
\hline 21 & 簕竹属 Bambusa & 流苏箪竹 Bambusa fimbriligulata & 1 & 2 \\
\hline 22 & 簕竹属 Bambusa & 鸡窦簕竹 Bambusa funghomii & 1 & 5 \\
\hline 23 & 簕竹属 Bambusa & 坭竹 Bambusa gibba & 9 & 28 \\
\hline 24 & 簕竹属 Bambusa & 鱼肚腩竹 Bambusa gibboides & 1 & 2 \\
\hline 25 & 簕竹属 Bambusa & 油簕竹 Bambusa lapidea & 9 & 15 \\
\hline 26 & 簕竹属 Bambusa & 孝顺竹 Bambusa multiplex & 27 & 48 \\
\hline 27 & 簕竹属 Bambusa & 绿竹 Bambusa oldhamii & 9 & 18 \\
\hline 28 & 簕竹属 Bambusa & 米笁竹 Bambusa pachinensis & 4 & 8 \\
\hline 29 & 簕竹属 Bambusa & 撑篙竹 Bambusa pervariabilis & 16 & 40 \\
\hline 30 & 簕竹属 Bambusa & 石竹仔 Bambusa piscatorum & 1 & 6 \\
\hline 31 & 簕竹属 Bambusa & 甲竹 Bambusa remotiflora & 5 & 13 \\
\hline 32 & 簕竹属 Bambusa & 木竹 Bambusa rutila & 4 & 15 \\
\hline 33 & 簕竹属 Bambusa & 车筒竹 Bambusa sinospinosa & 11 & 25 \\
\hline 34 & 簕竹属 Bambusa & 青皮竹 Bambusa textilis & 17 & 34 \\
\hline 35 & 簕竹属 Bambusa & 俯竹 Bambusa tulda & 1 & 4 \\
\hline 36 & 簕竹属 Bambusa & 青秆竹 Bambusa tuldoides & 36 & 87 \\
\hline 37 & 簕竹属 Bambusa & 佛肚竹 Bambusa ventricosa & 8 & 24 \\
\hline 38 & 簕竹属 Bambusa & 龙头竹 Bambusa vulgaris & 11 & 25 \\
\hline 39 & 单枝竹属 Bonia & 单枝竹 Bonia saxatilis & 1 & 1 \\
\hline 40 & 空竹属 Cephalostachyum & 香糯竹 Cephalostachyum pergracile & 1 & 4 \\
\hline 41 & 方竹属 Chimonobambusa & 缅甸方竹 Chimonobambusa armata & 1 & 1 \\
\hline
\end{tabular}


吴仁武, 南歆格, 晏海, 杨凡, 史琰, 包志毅 (2021) 美国在华采集竹类植物标本的历史(1840-2010 年). 生 物多样性, 29, 960-970. http://www.biodiversity-science.net/CN/10.17520/biods.2021029

\begin{tabular}{|c|c|c|c|c|}
\hline 序号 No. & 属 Genus & 物种 Species & 号数 Numbers & 份数 Sheets \\
\hline 42 & 方竹属 Chimonobambusa & 方竹 Chimonobambusa quadrangularis & 3 & 6 \\
\hline 43 & 方竹属 Chimonobambusa & 八月竹 Chimonobambusa szechuanensis & 1 & 7 \\
\hline 44 & 牡竹属 Dendrocalamus & 勃氏甜龙竹 Dendrocalamus brandisii & 1 & 2 \\
\hline 45 & 牡竹属 Dendrocalamus & 福贡龙竹 Dendrocalamus fugongensis & 1 & 2 \\
\hline 46 & 牡竹属 Dendrocalamus & 龙竹 Dendrocalamus giganteus & 1 & 2 \\
\hline 47 & 牡竹属 Dendrocalamus & 麻竹 Dendrocalamus latiflorus & 28 & 66 \\
\hline 48 & 牡竹属 Dendrocalamus & 牡竹 Dendrocalamus strictus & 2 & 5 \\
\hline 49 & 牡竹属 Dendrocalamus & 西藏牡竹 Dendrocalamus tibeticus & 1 & 1 \\
\hline 50 & 藤竹属 Dinochloa ${ }^{(1)}$ & 无耳藤竹 Dinochloa orenuda & 1 & 4 \\
\hline 51 & 藤竹属 Dinochloa & 毛藤竹 Dinochloa puberula & 1 & 4 \\
\hline 52 & 藤竹属 Dinochloa & 藤竹 Dinochloa utilis & 1 & 4 \\
\hline 53 & 箭竹属 Fargesia & 斜倚箭竹 Fargesia declivis & 1 & 1 \\
\hline 54 & 箭竹属 Fargesia & 黑穗箭竹 Fargesia melanostachys & 2 & 3 \\
\hline 55 & 箭竹属 Fargesia & 神农箭竹 Fargesia murielae & 1 & 5 \\
\hline 56 & 箭竹属 Fargesia & 华西箭竹 Fargesia nitida & 2 & 5 \\
\hline 57 & 箭竹属 Fargesia & 䊁花箭竹 Fargesia scabrida & 2 & 5 \\
\hline 58 & 箭竹属 Fargesia & 腾冲箭竹 Fargesia solida & 1 & 1 \\
\hline 59 & 箭竹属 Fargesia & 箭竹 Fargesia spathacea & 6 & 8 \\
\hline 60 & 贡山竹属 Gaoligongshania & 贡山竹 Gaoligongshania megalothyrsa & 2 & 2 \\
\hline 61 & 巨竹属 Gigantochloa & 滇竹 Gigantochloa felix & 1 & 3 \\
\hline 62 & 巨竹属 Gigantochloa & 毛笋竹 Gigantochloa levis & 1 & 3 \\
\hline 63 & 箬竹属 Indocalamus & 粽巴箬竹 Indocalamus herklotsii & 7 & 19 \\
\hline 64 & 箬竹属 Indocalamus & 阔叶箬竹 Indocalamus latifolius & 7 & 20 \\
\hline 65 & 箬竹属 Indocalamus & 箬叶竹 Indocalamus longiauritus & 11 & 28 \\
\hline 66 & 箬竹属 Indocalamus & 水银竹 Indocalamus sinicus & 3 & 17 \\
\hline 67 & 箬竹属 Indocalamus & 箬竹 Indocalamus tessellatus & 2 & 4 \\
\hline 68 & 大节竹属 Indosasa & 大节竹 Indosasa crassiflora & 1 & 1 \\
\hline 69 & 大节竹属 Indosasa & 摆竹 Indosasa shibataeoides & 5 & 9 \\
\hline 70 & 梨竹属 Melocanna & 梨竹 Melocanna humilis & 1 & 2 \\
\hline 71 & 少穗竹属 Oligostachyum & 细柄少穗竹 Oligostachyum gracilipes & 1 & 2 \\
\hline 72 & 少穗竹属 Oligostachyum & 林仔竹 Oligostachyum nuspiculum & 6 & 31 \\
\hline 73 & 少穗竹属 Oligostachyum & 毛稃少穗竹 Oligostachyum scopulum & 2 & 12 \\
\hline 74 & 刚竹属 Phyllostachys & 石绿竹 Phyllostachys arcana & 1 & 2 \\
\hline 75 & 刚竹属 Phyllostachys & 人面竹 Phyllostachys aurea & 10 & 18 \\
\hline 76 & 刚竹属 Phyllostachys & 毛竹 Phyllostachys edulis & 10 & 34 \\
\hline 77 & 刚竹属 Phyllostachys & 甜笋竹 Phyllostachys elegans & 6 & 11 \\
\hline 78 & 刚竹属 Phyllostachys & 曲竿竹 Phyllostachys flexuosa & 6 & 25 \\
\hline 79 & 刚竹属 Phyllostachys & 水竹 Phyllostachys heteroclada & 20 & 46 \\
\hline 80 & 刚竹属 Phyllostachys & 实心竹 Phyllostachys heteroclada f. solida & 4 & 4 \\
\hline 81 & 刚竹属 Phyllostachys & 台湾桂竹 Phyllostachys makinoi & 1 & 2 \\
\hline 82 & 刚竹属 Phyllostachys & 美竹 Phyllostachys mannii & 1 & 1 \\
\hline
\end{tabular}

(1) 莫古礼发表的 3 种藤竹经此后的中国植物学家鉴定认为很难肯定其属于藤竹属(Dinochloa), 因为至今尚未见到有花标 本, 分类位置存疑。 
吴仁武，南歆格，晏海，杨凡，史琰，包志毅 (2021) 美国在华采集竹类植物标本的历史(1840-2010 年). 生 物多样性, 29, 960-970. http://www.biodiversity-science.net/CN/10.17520/biods.2021029

\begin{tabular}{|c|c|c|c|c|}
\hline 序号 No. & 属 Genus & 物种 Species & 号数 Numbers & 份数 Sheets \\
\hline 83 & 刚竹属 Phyllostachys & 篌竹 Phyllostachys nidularia & 36 & 75 \\
\hline 84 & 刚竹属 Phyllostachys & 紫竹 Phyllostachys nigra & 25 & 44 \\
\hline 85 & 刚竹属 Phyllostachys & 毛金竹 Phyllostachys nigra var. henonis & 9 & 21 \\
\hline 86 & 刚竹属 Phyllostachys & 早园竹 Phyllostachys propinqua & 2 & 9 \\
\hline 87 & 刚竹属 Phyllostachys & 桂竹 Phyllostachys reticulata & 48 & 109 \\
\hline 88 & 刚竹属 Phyllostachys & 红边竹 Phyllostachys rubromarginata & 2 & 4 \\
\hline 89 & 刚竹属 Phyllostachys & 金竹 Phyllostachys sulphurea & 3 & 4 \\
\hline 90 & 刚竹属 Phyllostachys & 刚竹 Phyllostachys sulphurea var. viridis & 4 & 8 \\
\hline 91 & 刚竹属 Phyllostachys & 黄皮绿筋竹 Phyllostachys sulphurea var. viridis f. youngii & 1 & 1 \\
\hline 92 & 刚竹属 Phyllostachys & 硬头青竹 Phyllostachys veitchiana & 1 & 2 \\
\hline 93 & 刚竹属 Phyllostachys & 早竹 Phyllostachys violascens & 3 & 5 \\
\hline 94 & 刚竹属 Phyllostachys & 乌哺鸡竹 Phyllostachys vivax & 4 & 9 \\
\hline 95 & 苦竹属 Pleioblastus & 苦竹 Pleioblastus amarus & 7 & 10 \\
\hline 96 & 苦竹属 Pleioblastus & 菲白竹 Pleioblastus fortunei & 1 & 1 \\
\hline 97 & 苦竹属 Pleioblastus & 大明竹 Pleioblastus gramineus & 2 & 3 \\
\hline 98 & 苦竹属 Pleioblastus & 斑苦竹 Pleioblastus maculatus & 1 & 5 \\
\hline 99 & 苦竹属 Pleioblastus & 川竹 Pleioblastus simonii & 1 & 1 \\
\hline 100 & 矢竹属 Pseudosasa & 茶秆竹 Pseudosasa amabilis & 14 & 37 \\
\hline 101 & 矢竹属 Pseudosasa & 托竹 Pseudosasa cantorii & 61 & 137 \\
\hline 102 & 矢竹属 Pseudosasa & 䉜竹 Pseudosasa hindsii & 16 & 68 \\
\hline 103 & 矢竹属 Pseudosasa & 矢竹 Pseudosasa japonica & 3 & 10 \\
\hline 104 & 赤竹属 Sasa & 赤竹 Sasa longiligulata & 3 & 9 \\
\hline 105 & 赤竹属 Sasa & 维氏熊竹 Sasa veitchii & 1 & 1 \\
\hline 106 & 箅䈐竹属 Schizostachyum & 薄竹 Schizostachyum chinense & 1 & 1 \\
\hline 107 & 箅笳竹属 Schizostachyum & 苗竹仔 Schizostachyum dumetorum & 8 & 35 \\
\hline 108 & 箅管竹属 Schizostachyum & 沙罗箪竹 Schizostachyum funghomii & 7 & 18 \\
\hline 109 & 箅筋竹属 Schizostachyum & 山骨罗竹 Schizostachyum hainanense & 8 & 35 \\
\hline 110 & 䉕筋竹属 Schizostachyum & / Schizostachyum lumampao ${ }^{2}$ & 1 & 2 \\
\hline 111 & 䉕筋竹属 Schizostachyum & 䉕笶竹 Schizostachyum pseudolima & 2 & 4 \\
\hline 112 & 业平竹属 Semiarundinaria & 山竹仔 Semiarundinaria shapoensis & 2 & 2 \\
\hline 113 & 我毛竹属 Shibataea & 倭竹 Shibataea kumasaca & 1 & 1 \\
\hline 114 & 唐竹属 Sinobambusa & 扛竹 Sinobambusa henryi & 2 & 3 \\
\hline 115 & 唐竹属 Sinobambusa & 竹仔 Sinobambusa humilis & 4 & 6 \\
\hline 116 & 唐竹属 Sinobambusa & 晾衫竹 Sinobambusa intermedia & 1 & 3 \\
\hline 117 & 唐竹属 Sinobambusa & 唐竹 Sinobambusa tootsik & 3 & 8 \\
\hline 118 & 唐竹属 Sinobambusa & 满山爆竹 Sinobambusa tootsik var. laeta & 4 & 8 \\
\hline 119 & 玉山竹属 Yushania & 短雉玉山竹 Yushania brevipaniculata & 2 & 6 \\
\hline 120 & 玉山竹属 Yushania & 紫花玉山竹 Yushania violascens & 1 & 3 \\
\hline
\end{tabular}

(2) Schizostachyum lumampao (Blanco) Merr., Amer. J. Bot. 3: 63 (1916). 该种分布于菲律宾, 本表中记录的该种标本为莫 古礼 1929 年 5 月在中山大学竹园所采集, 其竹园编号为 1348, 标本号为 18538, 现两份标本分别藏于美国自然历史博物 馆植物标本馆(标本编号为 136297)和中山大学植物标本室(标本编号为 SYS00010145)。 